\title{
Mice overexpressing human caspase 3 appear phenotypically normal but exhibit increased apoptosis and larger lesion volumes in response to transient focal cerebral ischaemia
}

\author{
LE Kerr ${ }^{*, 1}$, AL McGregor ${ }^{1}$, LEA Amet ${ }^{1}$, T Asada ${ }^{1,5}$, C Spratt ${ }^{1}$, \\ TE Allsopp ${ }^{1,3}$, AJ Harmar², S Shen ${ }^{2,4}$, G Carlson ${ }^{1}$, N Logan', \\ JS Kelly ${ }^{1}$ and J Sharkey ${ }^{1}$ \\ ${ }^{1}$ Fujisawa Institute of Neuroscience in Edinburgh, University of Edinburgh, \\ Edinburgh EH8 9JZ, UK \\ 2 Division of Neuroscience, University of Edinburgh, Edinburgh EH8 9JZ, UK \\ ${ }^{3}$ Stem Cell Sciences UK Ltd, Kings Buildings, West Mains Road, Edinburgh \\ EH9 3JQ, UK \\ ${ }^{4}$ Department of Biomedical Sciences, University of Aberdeen, Foresterhill, \\ Aberdeen AB25 2ZD, UK \\ ${ }^{5}$ Current address: Fujisawa Pharmaceutical Co Ltd, 1-6, Kashima 2-chome, \\ Yodogawa-ku, Osaka 532-8514, Japan \\ * Corresponding author: LE Kerr, FINE, University of Edinburgh, \\ 1 George Square, Edinburgh EH8 9JZ, UK. Tel: + 44-131-650-6936; \\ Fax: +44-131-667-9381; E-mail: Lorraine.Kerr@ed.ac.uk
}

Received 19.1.04; revised 18.2.04; accepted 1.3.04; published online 21.5.04 Edited by $\mathrm{J}$ Yuan

\begin{abstract}
Caspase 3 activation has been implicated in cell death following a number of neurodegenerative insults. To determine whether caspase genes can affect the susceptibility of cells to neurodegeneration, a transgenic mouse line was created, expressing human caspase 3 under control of its own promoter. The human gene was regulated by the murine homeostatic machinery and human procaspase 3 was expressed in the same tissues as mouse caspase 3. These novel transgenic mice appeared phenotypically and developmentally normal and survived in excess of 2 years. Behavioural assessment using the 5-choice serial reaction time task found no differences from wild-type littermates. Caspase activity was found to be tightly regulated under physiological conditions, however, significantly larger lesions were obtained when transgenic mice were subjected to focal cerebral ischaemia/reperfusion injury compared to wildtype littermates. These data demonstrate that mice overexpressing human caspase 3 are essentially normal, however, they have increased susceptibility to degenerative insults.

Cell Death and Differentiation (2004) 11, 1102-1111.

doi:10.1038/sj.cdd. 4401449

Published online 21 May 2004
\end{abstract}

Keywords: caspase 3; transgenic; apoptosis; ischaemia; stroke; neurodegeneration; 5-CSRTT

Abbreviations: 5-CSRTT, 5-choice serial reaction time task; $\mathrm{FISH}$, fluorescence in situ hybridization; MCAo, middle cerebral artery occlusion; Tg, transgenic; WT, wild type; YAC, yeast artificial chromosome

\section{Introduction}

Caspases are a large family of cysteine aspartyl-specific proteases that play a pivotal role in apoptotic cell death. ${ }^{1,2}$ They are the mammalian orthologues of the Caenorhabditis elegans death gene, CED-3 that is essential for cell death in the development of the worm. ${ }^{3,4}$ Caspases exist as inactive proenzymes which undergo proteolytic processing and dimerization to form the active enzymes. They are activated in a sequential manner and play a central role in the execution phase of apoptotic death cleaving many vital structural and regulatory proteins (reviewed by Fischer et al. ${ }^{5}$ ). Numerous biochemical and cell biological studies on the activation of caspases have been reported leading to the ordering of the proapoptotic proteases into a hierarchical cascade: with the apical or initiator caspases 8 and 9 cleaving and activating the effector caspases 3,6 and $7 .^{6-8}$ Using cell-free, immunodepleted extracts, caspase 3 was shown to be the primary executioner caspase. ${ }^{9}$ Although thymocytes and hepatocytes from caspase 3 knockout mice retained normal susceptibility to various apoptotic stimuli, ${ }^{10,11}$ brain development was profoundly affected in these animals. ${ }^{10}$ The decreased apoptosis observed in the brain suggested a critical role for caspase 3 in the development of the central nervous system. Caspase 3 has also been implicated in cell death following a number of neurodegenerative insults including global ischaemia, ${ }^{12,13}$ focal ischaemia, ${ }^{14-19}$ transient ischaemia of the spinal cord, ${ }^{20}$ neonatal cerebral hypoxia-ischaemia, ${ }^{21-23}$ traumatic brain injury, ${ }^{24-26}$ Alzheimer's disease, ${ }^{27-29}$ Huntington's disease, ${ }^{30-32}$ and Parkinson's disease. ${ }^{33-37}$ It was therefore hypothesized that overexpression of caspase 3 may sensitize the animal to normal (physiological) apoptotic processes that occur during development and natural ageing and confer particular susceptibility to neurodegenerative insults. To test this hypothesis, a caspase 3 transgenic mouse line was generated using a yeast artificial chromosome (YAC) containing the human genomic DNA spanning the full-length gene including all regulatory elements. The development of these transgenic mice and their sensitivity to a neurodegenerative insult (focal cerebral ischaemia) were investigated.

\section{Results}

\section{Generation of transgenic lines and expression of caspase 3 transgene}

A human genomic YAC clone (35EB2) which had previously been shown to encompass the caspase 3 gene, ${ }^{38}$ was used for the construction of transgenic mice. Southern blot analysis, PCR and pulsed-field electrophoresis showed that YAC 35EB2 contained all seven exons and the $3^{\prime}$ untranslated 
region (UTR) of human caspase 3 , as well as $80 \mathrm{~kb}$ of upstream and $50 \mathrm{~kb}$ of downstream regulatory sequences (Figure 1a). Fluorescence in situ hybridization (FISH) studies on human neutrophils confirmed that the YAC was nonchimeric and mapped to the telomeric region of human chromosome 4 , which is coincident with the location of the caspase 3 gene ${ }^{38}$ (Figure 1b). Genotyping of 89 offspring born after microinjection by PCR analysis identified 10 transgenic founders, five of which transmitted the transgene. Southern blotting and PCR confirmed that the transgenic lines had integrated one to three copies of the YAC (data not shown). Two transgenic lines were characterized extensively C57BL/6J-Tg(CASP3)F18Fine and C57BL/6J-Tg(CASP3) F57Fine. Mice were backcrossed to $\mathrm{C} 57 \mathrm{BL} / 6 \mathrm{~J}$ for at least 10 generations to ensure congenicity and were born in expected ratios as predicted from Mendelian genetics. Northern analysis and RT-PCR of P6 brains demonstrated that the human gene was transcribed in transgenic mice but not wild-type (WT) littermates during development (Figure 2a, b). Western blotting with a human-specific antibody confirmed expression of human caspase 3 zymogen in these mice (Figure 2c). The spatial expression of the human form in the adult mouse was essentially identical to that of the murine protein with highest levels being detected in the spleen, thymus, liver, kidney and brain (Figure 3).

\section{Histological analysis}

Transgenic mice appeared to be phenotypically and developmentally normal and were essentially indistinguishable from their WT littermates throughout life which extended beyond 26 months. The anatomical organization of the brain and the cerebrovasculature were examined in detail using serial horizontal sections stained for acetyl cholinesterase (modified Karnovsky and Roots) and Nissl bodies (thionin) in both young and aged (24-month-old) mice. Comparable horizontal brain sections of transgenic and WT mice were examined in terms of organization and dimensions (Figure 4). Detailed inspection of the aged brains by four independent scorers failed to identify any differences between WT and transgenic brains. There were no significant differences in any of the measurements taken including cortical mantel size, cerebellar and hippocampal dimension and overall brain size. It was concluded that the caspase 3 transgenic mice were histologically normal.

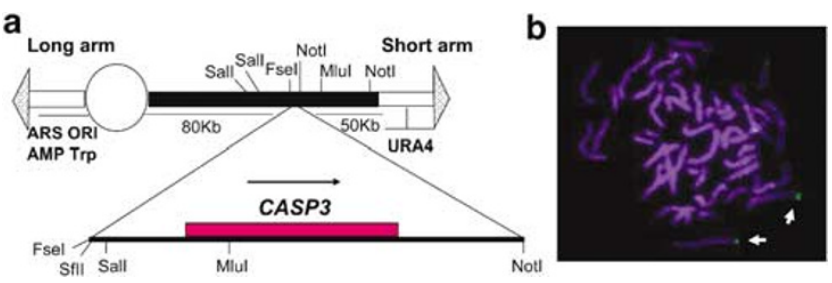

Figure 1 Characterization of YAC for generation of human caspase 3 transgenic mice. (a) Schematic representation of YAC 35EB2 which encompasses the human caspase 3 gene and approximately 80 and $50 \mathrm{~kb}$ of upstream and downstream regulatory elements, respectively. (b) FISH analysis of YAC 35EB2 on metaphase chromosomes of human neutrophils demonstrated that the YAC was nonchimeric and mapped to the telomeric region of human chromosome 4 (arrows)

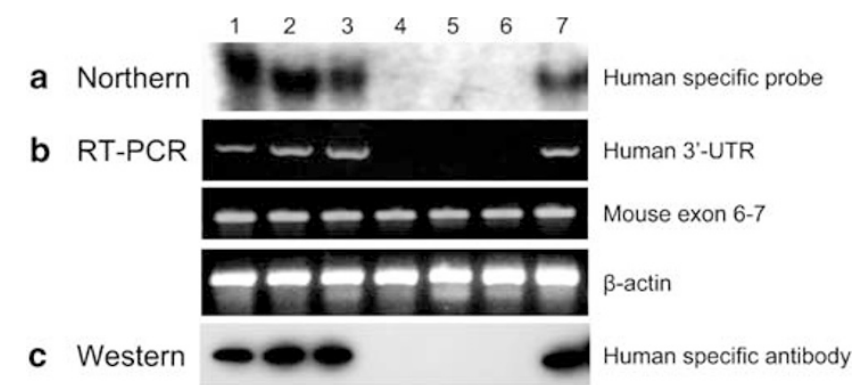

Figure 2 Expression of human caspase 3 in developing transgenic mouse brain. The expression of caspase 3 was analysed in a litter of seven pups at postnatal day 6 . Transgenic mice are in lanes 1, 2, 3 and 7 and WT littermates are in lanes 4, 5 and 6. (a) Northern blot analysis showing expression of the human caspase 3 gene. The probe used corresponds to a $0.6 \mathrm{~kb}$ fragment of the human $3^{\prime}$ UTR region. (b) RT-PCR analysis performed using human-specific caspase 3 primers (top panel), mouse-specific caspase 3 primers (middle panel) or mouse $\beta$-actin primers (bottom panel). (c) Western blot analysis of total brain lysate showing expression of the human procaspase 3 in transgenic brains but not those of WT littermates

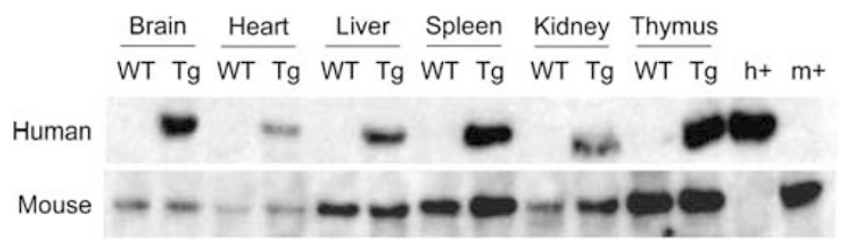

Figure 3 Similarities of spatial expression of mouse and human caspase 3 proteins in adult mice. The expression of human and mouse procaspase 3 in brain, heart, liver, spleen, kidney and thymus of wild-type (WT) and transgenic (Tg) mice was characterized by Western blot using antibodies recognizing specific for human (top panel) or mouse (bottom panel) caspase 3

\section{Behavioural assessment using 5-choice serial reaction time test}

The normal ageing process is associated with impairments in sustained attention as assessed in humans by the continuous performance test and in animals by the 5-choice serial reaction time task (5-CSRTT). ${ }^{39,40}$ As it was hypothesized that overexpression of human caspase 3 would exacerbate the cognitive decline associated with the normal ageing process, transgenic mice and age-matched WT littermates were assessed in the 5-CSRTT at 14, 20 and 27 months of age. In order to receive a liquid reward, mice were required to make a response at one of five locations following a brief light pulse. The initial training schedule lasted until the mice had attained asymptotic performance at $1 \mathrm{~s}$ stimulus duration or 40 daily sessions had elapsed. Transgenic mice acquired the 5CSRTT as readily as their WT littermates (Figure 5a). ANOVA confirmed no significant main effect of genotype on the cumulative number of trials taken to reach asymptotic performance $\left(F_{(1,42)}=0.14, P=0.71\right)$. Asymptotic performance, measured in terms of mean accuracy from three consecutive sessions revealed no effect of ageing $\left(F_{(2,23)}=0.98, P=0.39\right)$ nor of transgene $\left(F_{(1,23)}=0.91\right.$, $P=0.35$; Figure $5 b)$. These data suggest that overexpression of human caspase 3 is not deleterious and that under normal physiological conditions, caspase 3 activity is tightly regulated. However, an alternative explanation is that the mouse 


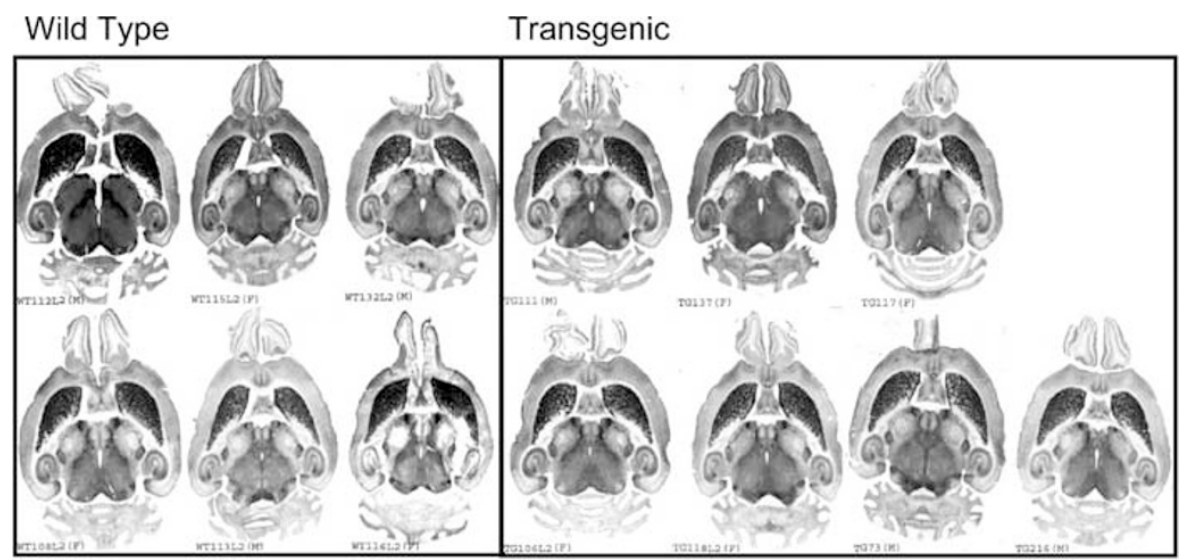

Figure 4 Histological assessment of caspase 3 transgenic mice. Horizontal brain sections from seven transgenic mice and six WT littermates aged 24 months were stained for acetyl cholinesterase. Multiple measurements were compared but no differences between the mice were found

machinery is not able to process the human proenzyme. In order to verify that the transgenic human proenzyme could be cleaved and activated, further biochemical experiments were performed.

\section{Activation of human procaspase 3 in vitro}

Human procaspase 3 in brain extracts from transgenic mice could be biochemically activated by treatment with recombinant active human caspase 6 or 8 in vitro (Figure 6). The intrinsic murine apoptotic machinery could also process the human proenzyme in cultured cells. Cerebellar granule cells were cultured from transgenic mice and WT littermates and apoptosis was induced with serum deprivation under conditions of low potassium. Western blotting studies with a humanspecific antibody confirmed that the human procaspase 3 was cleaved under these conditions (Figure 7). This processing was not confined to neuronal cells as caspase 3 cleavage was also detected in cultured splenocytes after the induction of apoptosis with Fas ligand (Figure 6). Furthermore, caspase 3like activity was measured by DEVD cleavage in P6 brain extracts and no differences could be detected between transgenic and WT mice (data not shown). These data demonstrated that the human proenzyme can be cleaved and activated by the mouse machinery but under normal physiological conditions, caspase 3 activity appears to be tightly regulated. However, it was hypothesized that overexpression of human caspase 3 proenzyme may sensitize mice to degenerative insults.

\section{Caspase 3 activation in vivo following cerebral ischaemia}

To test this hypothesis that overexpression of caspase 3 would sensitize mice to ischaemic brain damage, transgenic and WT littermate mice were subjected to 30,45 and 60 min of middle cerebral artery occlusion (MCAo). WT mice exhibited qualitatively different patterns of damage with increasing ischaemic duration and the pattern of damage in transgenic mice was also qualitatively different from that observed in WT littermates (Figure 8a). A $30 \mathrm{~min}$ MCAo failed to produce damage in the majority of WT animals examined while the majority of those subjected to 45 min MCAo exhibited lesions. At both time points the lesions were restricted to the striatum, in those WT animals showing ischaemic damage. In contrast, all transgenic mice subjected to 30 and $45 \mathrm{~min}$ MCAo displayed ischaemic damage to the striatum. Moreover, at 45 min the majority of transgenic mice also exhibited cortical damage. All transgenic and WT animals subjected to $60 \mathrm{~min}$ MCAo had large infarcts with both cortical and striatal components. No damage was observed outwith the vasculature territory of the MCA in any of the animals investigated. Quantitative histopathology demonstrated that transgenic animals developed larger hemispheric lesions than their WT littermates following each of the ischaemic insults (Figure 8b). This was confirmed by two-way ANOVA which revealed a significant effect of both ischaemic duration $\left(\mathrm{F}_{(2,35)}=7.9\right.$; $P=0.002)$ and transgene $\left(\mathrm{F}_{(1,35)}=21.9 ; P<0.001\right)$.

\section{Immunohistochemistry of cleaved caspase-3 and TUNEL staining}

Immunocytochemistry was performed on sections from transgenic and WT animals $24 \mathrm{~h}$ after a $30 \mathrm{~min}$ ischaemic insult (Figure 9a). Cleaved caspase 3- and TUNEL-positive cells were quantified in the ischaemic striatum of transgenic and WT animals. These data showed that transgenic animals exhibited a significantly higher number of active caspase 3and TUNEL-positive cells within the ischaemic striatum than their WT littermates $(P=0.028$; Figure $9 \mathrm{~b})$.

\section{Discussion}

A transgenic mouse line overexpressing human caspase 3 was made using a previously characterized human genomic YAC clone. ${ }^{38}$ This YAC encompassed the human caspase 3 gene and, as expected, hybridized to the telomeric region of human chromosome 4, the chromosomal location of the caspase 3 gene. ${ }^{38,41}$ Although YAC transgenic mice usually show position-independent expression of the encoded genes, ${ }^{42}$ mice were bred to congenicity with C57BL/6J by backcrossing for at least 10 generations and characterized. 
a

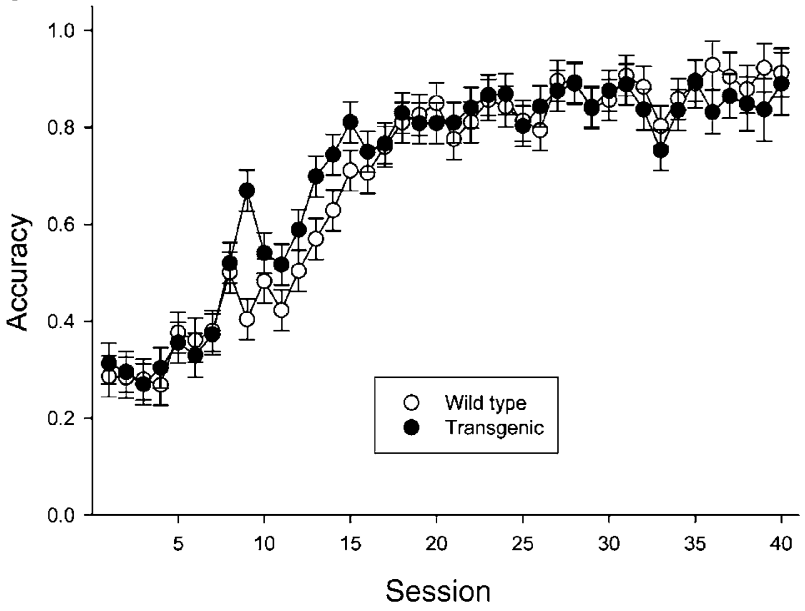

b

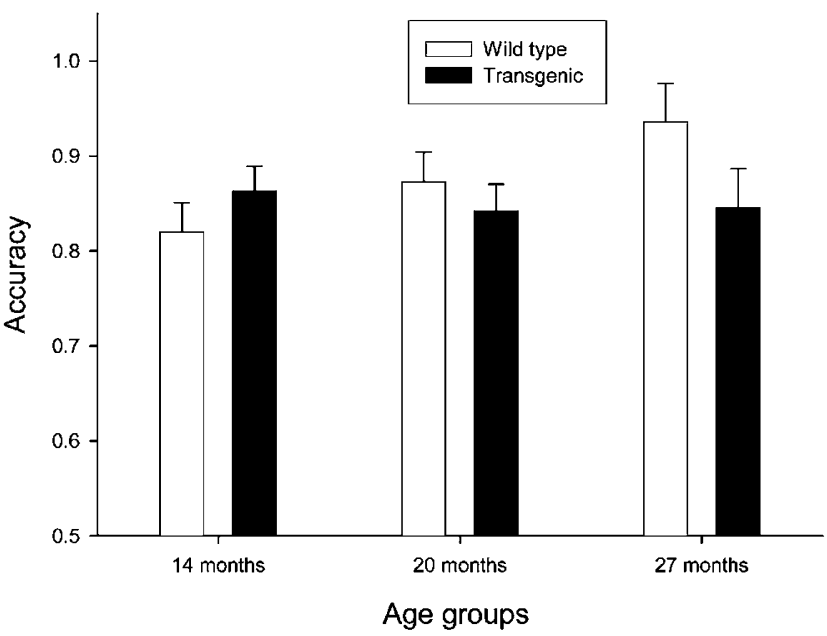

Figure 5 Behavioural assessment using 5-choice serial reaction time test (a) Acquisition of the 5-CSRTT in transgenic mice and age-matched WT littermates. Data are presented as mean accuracy \pm S.E.M. from the initial training period. (b) Asymptotic performance assessed at 14, 20 and 27 months of age. Data are presented as mean \pm S.E.M. accuracy derived from three consecutive sessions once asymptotic performance had been established. Data were analysed by twoway ANOVA and show no significant differences between groups during acquisition $(F(1,42)=0.14, P=0.71)$ or at final levels of performance either by age $(F(2,23)=0.98, P=0.39)$ or genotype $(F(1,23)=0.91, P=0.35)$

The human caspase 3 transgenic mice were essentially normal as no obvious phenotypic, developmental or histological differences were observed. The human protein was expressed in the same tissues as its murine counterpart. Highest expression levels were found in the spleen, thymus, liver, kidney and brain in agreement with published data for caspase 3 mRNA $^{43,44}$ and protein ${ }^{44}$ levels. This demonstrated that in vivo the human gene was subject to similar control to the mouse gene. Although detailed analysis of the mouse promoter has not been reported, the mouse and human caspase 3 cDNA sequences are $83 \%$ identical (HomoloGene database ${ }^{45}$ ) while at the protein level they are $87 \%$ identical (UniGene database ${ }^{45}$ ). Therefore, it is likely that the gene promoters are similar in these two species also. Supporting this theory, the human and rat caspase 3 promoters show a

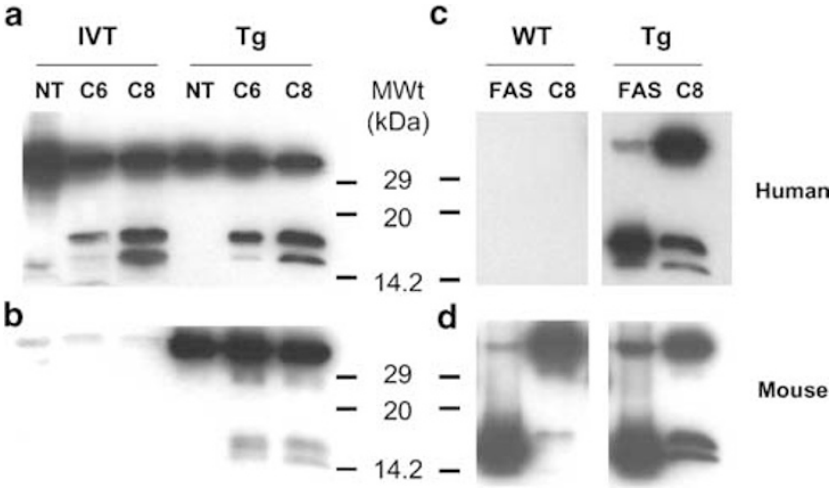

Figure 6 Biochemical activation of human caspase 3 transgene in vitro. (a) Human procaspase 3 expressed in vitro (IVT) or in transgenic brain extracts (Tg) was cleaved by addition of recombinant active human caspase 6 (C6) or 8 (C8). No cleavage products were obtained in untreated caspase 3 lanes (NT). (b) A similar blot probed with an antibody specific for murine caspase 3 demonstrated that mouse caspase 3 was also cleaved by the addition of recombinant active human caspase 6 or 8 . (c) Cleavage of human caspase 3 was detected in splenocytes treated with Fas (Fas) or cerebellar brain tissue extracts treated with recombinant human caspase 8 (C8) from transgenic (Tg) but not WT littermate mice. (d) A similar blot probed for mouse caspase 3 demonstrated that mouse caspase 3 was also cleaved by these treatments in both types of mouse

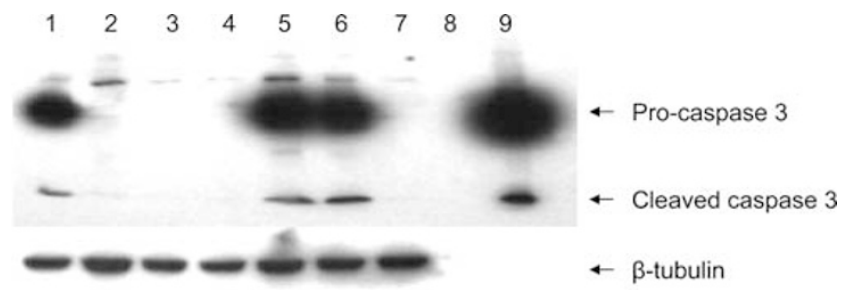

Figure 7 Human caspase 3 activation in cultured cells. Cerebellar granule cells were cultured and apoptosis induced with potassium serum deprivation. Western blot analysis with a human caspase 3-specific antibody demonstrated processing of the human procaspase 3 to its cleaved product in transgenic samples (lanes 1 , 5 and 6) but not in WT littermates (lanes 2, 3, 4 and 7). No sample was loaded in lane 8 and lane 9 contained a positive control sample (SH-SY5Y human neuroblastoma cell line treated with staurosporine). Equal loading of lanes was confirmed with $\beta$-tubulin (bottom panel)

$61.8 \%$ identity ${ }^{46}$ suggesting that the regulatory regions of the caspase 3 gene are conserved between mammalian species and likely to be subject to the same regulatory controls.

Caspase 3 has been termed the 'common executioner' for various cell death pathways and is therefore produced as an inactive proenzyme, which has to undergo proteolytic cleavage and dimerization to produce the active enzyme. As an executioner caspase, procaspase 3 can activated by both the extrinsic (death-receptor-mediated) and the intrinsic (mitochondrial) pathways of programmed cell death (reviewed by Ashe and Berry ${ }^{47}$ ). In the extrinsic pathway, binding of a ligand (such as Fas ligand) to its death receptor (Fas receptor) activates the signalling pathway resulting in caspase 8mediated cleavage of procaspase 3 . It was possible to cleave the human proenzyme by addition of recombinant human caspase 8 in vitro and by Fas ligand treatment of splenocyte cultures from transgenic mice. Processing of the human procaspase 3 was also initiated by withdrawal of trophic support from cultured cerebellar granule cells and by direct treatment with active human caspase 6 as had previously 
a

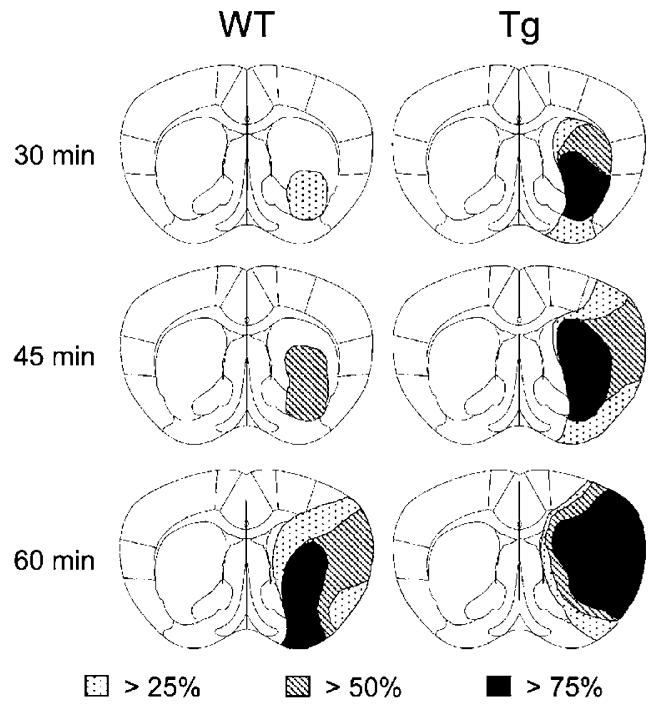

b

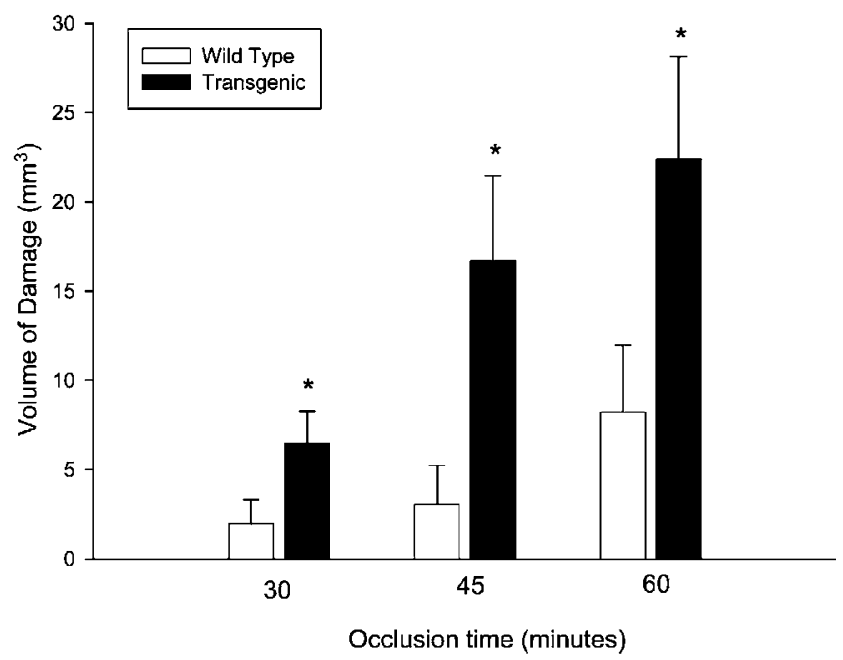

Figure 8 Caspase 3 overexpressing mice exhibit larger lesions than nontransgenic littermates following MCA occlusion. (a) Incidence maps showing the patterns of ischaemic damage obtained in transgenic $(\mathrm{Tg})$ mice and WT littermates at the level of the striatum (Bregma +0.74 ) following 30,45 or 60 min of transient MCA occlusion. (b) Measurement of total lesion volume produced by transient MCA occlusion (30, 45 or $60 \mathrm{~min}$ ) measured (over 9 levels) at $24 \mathrm{~h}$ using thionin staining. Two-way ANOVA showed that there was a significant effect of time $(\mathrm{F}(2,35)=7.9, P=0.002)$ and genotype $(\mathrm{F}(1,35)=21.9, P<0.001)$. Data are mean \pm S.E.M., $n=5-9$ mice per group

been shown for rodent caspase $3 .^{48,49}$ Taken together, these data demonstrated that the transgene contained the fulllength human gene and that once produced, the human proenzyme could be cleaved and activated by both human and murine machinery. However in vivo, the human gene and protein appeared to be regulated as normal for their murine counterparts suggesting that caspase activity is tightly regulated under physiological conditions. This is hardly surprising considering the high degree of homology between the human and mouse caspase 3 amino-acid sequences which are $87 \%$ identical (UniGene database ${ }^{45}$ ).
It was hypothesized that the increased levels of procaspase 3 may sensitize the mice to the normal ageing process and to acute pathophysiological insults such as stroke. However, the present data provide little evidence that the presence of the human proenzyme affected the normal ageing process: transgenic mice lived for more than 2 years and were histologically normal when brains were analysed at 24 months. Moreover, these transgenic mice were indistinguishable from their WT littermates when tested at 14, 20 and 27 months of age in the 5-CSRTT. This test was used because it is an attentional task similar to the continuous performance test used to assess attentional function in man. The normal ageing process in humans is associated with impairments in sustained attention ${ }^{50,51}$ and similar age-related deficits have been detected in rats using the 5 -CSRTT ${ }^{39,52,53}$ Although this test has been used in mice, ${ }^{54,55}$ no ageing studies have previously been reported. Interestingly no age-related deficit was found in either the transgenic or WT mice and all ages of mice performed the task equally well. As no age-related deficits were seen in this test of sustained attention, other tests of cognitive function (e.g. of spatial memory) need to be performed to fully elucidate what, if any, impairments are revealed due to ageing in the transgenic compared to WT mice.

Several lines of evidence point to caspase 3 as a mediator of ischaemic cell death. Caspase 3 activation has been detected following focal (and global) ischaemic insults to the brain ${ }^{14-19}$ where it coincides with areas of enhanced apoptotic cell death ${ }^{14}$ and treatment with caspase 3 inhibitors has been reported to reduce infarct size following MCA occlusion. ${ }^{14,56-58}$ Moreover, studies in caspase 3-deficient mice indicate that these animals are relatively resistant to ischaemic insults with smaller lesions than their WT littermates. ${ }^{59}$ In keeping with these literature reports, the studies presented here demonstrate that mice overexpressing human caspase 3 exhibit more apoptotic cell death and larger cerebral lesions than their WT littermates. Similarly, heart-targeted overexpression of caspase 3 resulted in increased lesion size following myocardial ischaemia-reperfusion. ${ }^{60}$

To test the hypothesis that caspase 3 overexpression would sensitize the brain to ischaemic damage, we chose to examine three different ischaemic insults. Brief occlusion of the MCA in C57BL/6J mice has been reported to produce an ischaemic lesion that is restricted to the striatum while more prolonged ischaemia results in damage to both striatum and overlying cortex, although there is evidence that the precise threshold for induction of cortical damage may differ from one laboratory to another. ${ }^{61-63}$ In the present study, human caspase 3 overexpressing mice exhibited larger and more consistent lesions at each of the three time points investigated. Moreover, in the $45 \mathrm{~min}$ occlusion group, where damage was restricted to the striatum of WT littermates, the transgenic mice exhibited consistent damage to both cortex and striatum. No differences in cerebrovascular anatomy were detected between transgenic and WT mice; therefore, the increased lesion volumes could not be attributed to this factor. These results suggest that human caspase 3 overexpression does sensitize the brain to ischaemic damage.

Initial studies reported that caspase 3 knockout mice have profound defects of apoptosis in the central nervous system 
a

WT

$\operatorname{Tg}$
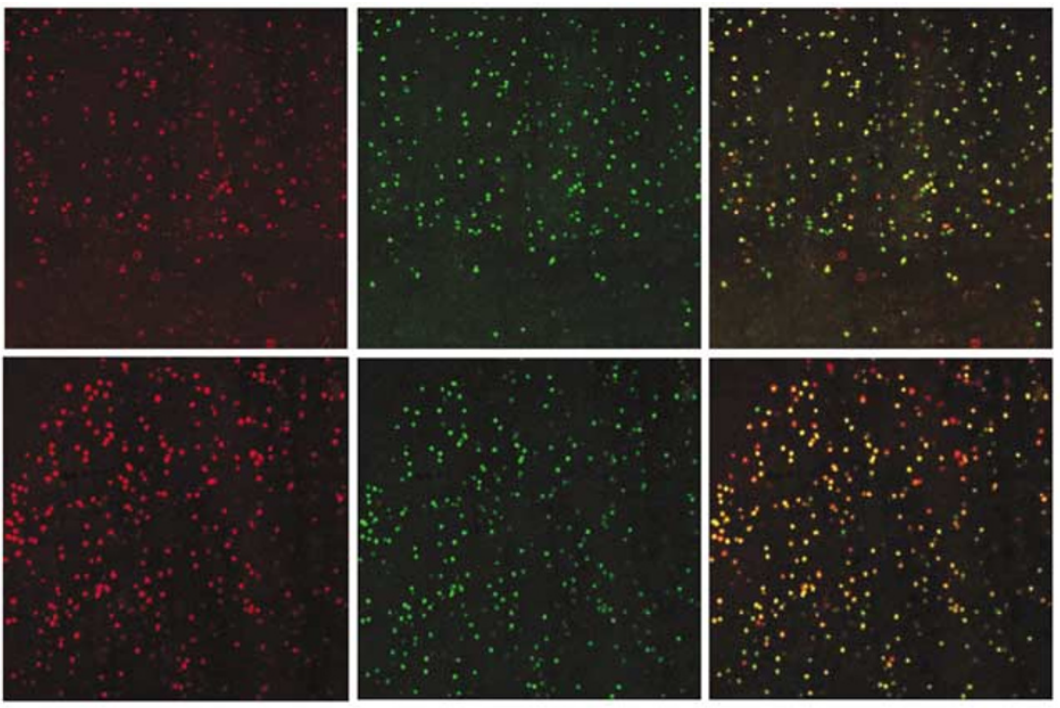

TUNEL

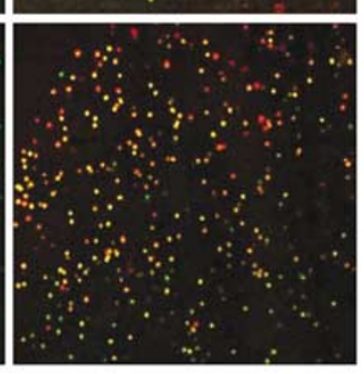

Merged b

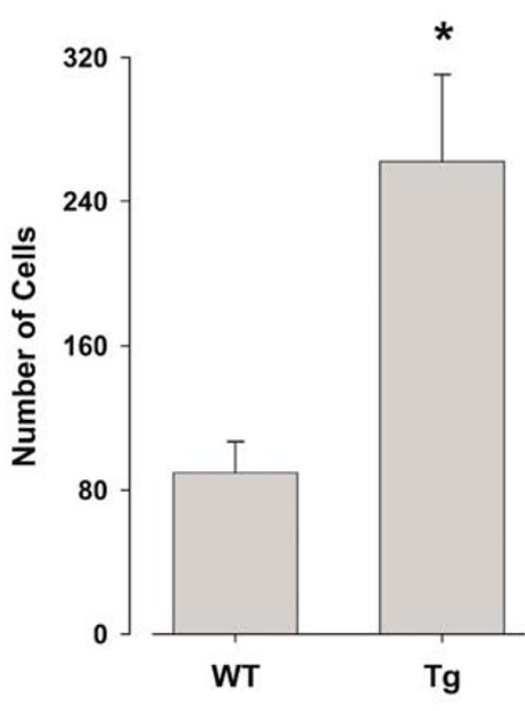

Figure 9 Detection of active caspase 3 in WT and transgenic ischaemic brains by confocal microscopy. Mice were subjected to 30 min MCA occlusion and brains processed for immunocytochemistry at $24 \mathrm{~h}$. (a) Brain sections within the MCA territory were stained with an antibody directed against both mouse and human processed caspase 3 (red) and TUNEL (green) and representative images within the ischaemic striatum are shown. Superimposition of the two fluorescent images (right panels) indicate that there is a good correlation between caspase 3 activation and TUNEL staining (yellow). (b) Quantitative analysis demonstrated that transgenic animals exhibited a higher number of active caspase 3 - and TUNEL-positive cells within the ischaemic striatum than their WT littermates. Data are mean \pm S.E.M., $n=3$ mice per group, $P=0.028$

showing decreased apoptosis in the brain resulting in hyperplasia and premature lethality with the mice dying at 1-3 weeks of age. ${ }^{10}$ However, thymocytes and hepatocytes from these animals retained normal susceptibility to various apoptotic stimuli demonstrating the redundancy of caspases at least in these peripheral cells. ${ }^{10,11}$ As the brains of the human caspase 3 transgenic mice also develop normally, the transgene must be regulated by the murine machinery so that the natural cell death occurring during brain development proceeds in its usual fashion. In contrast to the neurodegenerative stimulus response in the adult, overexpression of human caspase 3 did not seem to sensitize cells to cell death occurring during normal brain development. These data suggest that although caspase 3 participates in the cell death processes which occur during development of the brain and after a neurological insult, a fundamental difference exists perhaps in the activating pathways. However, it has been shown that the background strain may be important in determining the phenotype seen in genetically modified mice. The neurodevelopmental abnormalities seen in caspase 3-nullizygous mice have been shown to be strain dependent where mice on a 129/Sv background are severely affected while those on a C57BL/6 background are not affected and survive to adulthood suggesting the presence of a strainspecific genetic modifier. ${ }^{64}$ Furthermore, in the forebrain of 129/Sv mouse embryos, numerous cells were found to be positive for cleaved caspase 3 immunoreactivity but only slight staining was seen in C57BL/6 embryos. ${ }^{65}$ The transgenic human caspase 3 mice reported here have been bred to congenicity on a C57BL/6J background and this may be the reason why overexpression of human caspase 3 did not seem to sensitize cells to cell death occurring during normal brain development.
There is a growing list of substrates cleaved by caspases and suggested roles for caspases in other cellular processes such as cell cycle regulation and cellular differentiation have been proposed. ${ }^{5}$ There is also mounting evidence that the apoptotic pathway is involved in normal neuronal plasticity ${ }^{66}$ and a surprising role for caspase 3 activation as essential in neuroprotective preconditioning was recently demonstrated. ${ }^{67}$ As the many diverse functions of caspases become apparent it would be interesting to see what effects (if any) caspase 3 overexpression had in these systems. Therefore, these novel human caspase 3 transgenic mice may help elucidate the role of caspase 3 in the many cellular processes in which it may be involved.

\section{Materials and Methods}

All animal work was performed under license by the UK Home Office subject to the Animal (Scientific Procedures) Act of 1986.

\section{Construction of human caspase 3 YAC transgenic mice}

YAC 35EB2 was selected from the ICI human YAC library ${ }^{68}$ (UK HGMP Resource Centre, Cambridge, UK) because of its association with the human caspase 3 gene. $^{38}$ The YAC DNA was isolated from transformed yeast as described ${ }^{69}$ and its integrity tested by restriction mapping and $\mathrm{FISH}$ on metaphase chromosomes of human neutrophils ${ }^{70}$ using a Biotin-dUTP nick translation kit (Roche Diagnostics, Lewes, UK). A total of $840 \mathrm{~F} 1 \mathrm{C} 57 \mathrm{BL} / 6 \mathrm{~J} \times \mathrm{CBA}$ fertilized eggs were microinjected ${ }^{71}$ with a preparation of highly purified YAC DNA ${ }^{72}$ $(2 \mathrm{ng} / \mu \mathrm{l})$ yielding 89 live births $(10 \%)$, of which 10 were found to be transgenic (11\%). 


\section{Genotyping and mouse breeding}

Genotyping was performed on tail tips or ear punches. Tail tipping was performed under halothane/nitrous oxide anaesthesia and tail DNA was obtained by proteinase K (Promega, Southampton, UK) treatment. ${ }^{73}$ Ear clips were heated at $95^{\circ} \mathrm{C}$ for $20 \mathrm{~min}$ in $25 \mathrm{mM} \mathrm{NaOH} / 0.2 \mathrm{mM}$ EDTA then neutralized by the addition of an equal volume of $40 \mathrm{mM}$ Tris- $\mathrm{HCl}$. Three primer pairs corresponding to both YAC ends (long arm: forward primer $5^{\prime}$ ATT GCT AAC GCA GTC AGG CAC C-3', reverse primer 5'-TAG TGG CTC CAA GTA GCG AAG C-3', producing 278 bp product; and short arm: forward primer 5'-TCT CCG AAC AGA AGG AAG AAC G-3', reverse primer $5^{\prime}$-TGT TAC TTC TTC TGC CGC CTG C-3', producing $568 \mathrm{bp}$ product) and human caspase 3 (3'-UTR: forward primer $5^{\prime}$-TGA TGA TGT GGA AGA ACT TAG G-3', reverse primer $5^{\prime}$-ACG GCT CCG CAC CTG CTG AGG C-3 producing 944 bp product) were initially used for PCR genotyping. Southern blotting confirmed the initial PCR results. Transgenic founders were crossed to C57BL/6J (Charles River, Margate, UK) to test for germline transmission of the full YAC DNA. Four transgenic lines were selected and assessed for expression of human caspase 3 by RT-PCR, Northern and Western blotting analysis. Of these lines, three (F18, F21 and F57) were found to express human caspase 3 and two lines (F18 and F57) were selected for further studies. The F18 and F57 lines were made congenic by successive backcrossing to C57BL/6J (Charles River) for at least 10 generations and named C57BL/6J-Tg(CASP3)F18Fine and C57BL/6J-Tg(CASP3)F57Fine, respectively according to the guidelines set out by the International Committee on Standardized Genetic Nomenclature for Mice and implemented through the Mouse Genomic Nomenclature Committee (MGNC). Wild-type (WT) littermates were used as controls in all experiments.

\section{RT-PCR and Northern blotting}

Total RNA was isolated from mouse brains using TriReagent (SigmaAldrich, Poole, UK) according to the manufacturer's instructions. A measure of $1-5 \mu \mathrm{g}$ of total brain RNA were reverse-transcribed (First Strand cDNA synthesis kit, Amersham Biosciences, Little Chalfont, UK) and used for subsequent PCR amplification. Primers specific for human caspase 3 were $5^{\prime}$-TGA TGA TGT GGA AGA ACT TAG G-3' (forward primer) and $5^{\prime}$-ACG GCT CCG CAC CTG CTG AGG C-3' (reverse primer) producing a product of $944 \mathrm{bp}$ from the $3^{\prime}-\mathrm{UTR}$; for mouse caspase 3 were 5'-GGC TTG CCA GAA GAT ACC GGT-3' (forward primer) and 5'-GCA TAA ATT CTA GCT TGT GCG CGT A-3' (reverse primer) producing a product of $150 \mathrm{bp}$ from exons $6-7$; and for $\beta$-actin were $5^{\prime}$-TCA TGA AGT GTG ACG TTG ACA TCC GT-3' (forward primer) and 5'-CCT AGA AGC ATT TGC GGT GCA CGA TG-3' (reverse primer) producing a product of $285 \mathrm{bp}$. For Northern blotting, $20 \mu \mathrm{g}$ of total brain RNA were electrophoresed on $1.2 \%$ formaldehyde agarose gel in MOPS buffer and transferred overnight onto Hybond-N (Amersham Biosciences) in $20 \times$ SSC. $^{73}$ Membranes were hybridized with a 600 bp human caspase 3-specific probe corresponding to the 3'-UTR (IMAGE EST 937366; UK HGMP Resource Centre, Cambridge, UK) using standard molecular procedures. $^{73}$

\section{Western blotting analysis}

Total protein was isolated from mouse brain (cerebellum) using TriReagent (Sigma-Aldrich) according to the manufacturer's instructions. Human caspase 3 cDNA clone in PCRII TOPO (Invitrogen, Paisley, UK) was transcribed and translated in vitro (TnT Quick Coupled Transcription/ Translation system, Promega). Treatment of brain extract or in vitro translated (IVT) caspase 3 with recombinant active human caspase 6 or 8 (BD Biosciences, Oxford, UK) was performed as previously described. ${ }^{49}$ Cerebellar granule neuron cultures were prepared from postnatal day 6 (P6) transgenic and WT littermates and apoptosis induced on the 7th day of in vitro culture in low $\mathrm{K}^{+}$medium (serum free Basal medium Eagles, $5 \mathrm{mM} \mathrm{KCl}$ ) as previously described. ${ }^{49}$ Splenocytes were cultured from adult caspase- 3 transgenic mice and WT littermates ${ }^{74,75}$ and apoptosis induced with anti-mouse Fas antibody ( $\alpha \mathrm{CD} 3 \varepsilon, \mathrm{BD}$ Biosciences) as described. $^{74}$

A measure of $30 \mu \mathrm{g}$ of protein were resolved by $12 \%$ SDS-PAGE and electroblotted onto PVDF membranes (Immobilon-P; Sigma-Aldrich) for $2 \mathrm{~h}$ at a constant voltage of $10 \mathrm{~V}$ using semi-dry apparatus. Blots were blocked by overnight incubation in TBS (Tris-buffered saline, $\mathrm{pH}$ 8.0) containing $0.05 \%$ Tween-20, 5\% nonfat milk powder. Caspase-3 was detected using commercial antibodies specific for human or mouse caspase 3 (both BD Biosciences 1/1000 dilution) or which recognized caspase 3 and cleaved caspase 3 from both species (both Cell Signaling Technology, Hitchin, UK; 1/1000 dilution). Bound antibody was detected using anti-mouse or anti-rabbit Ig conjugated to horseradish peroxidase (Amersham Biosciences, 1/2500 dilution) and enhanced chemiluminescence (ECL plus, Amersham Biosciences). To confirm equal loading of samples, blots were stripped of bound antibody (stripping buffer: $0.2 \mathrm{M}$ glycine $\mathrm{pH} 2.2,0.1 \%$ SDS, $0.1 \%$ Tween 20 ). Reincubation in ECL reagent confirmed that all bound antibody reagents were removed. Blots were blocked as described previously, incubated with an antibody against $\beta$ Tubulin (Sigma-Aldrich, 1/4000 dilution) and detected using anti-mouse lgHRP conjugate (Amersham Biosciences, 1/2500 dilution) and ECL.

\section{Behavioural assessment using 5-choice serial reaction time test}

Male transgenic animals $(n=7)$ and age-matched WT littermates $(n=5)$ were group-housed and tested 5 days a week during the light part of their cycle. Food was restricted to maintain animals at $85 \%$ of their free-feeding weight but water was available ad libitum. Training was carried out as previously described ${ }^{55}$ using 12-month-old animals. In summary, subjects were required to sustain attention to an array of five stimulus locations over a period of 120 trials or $25 \mathrm{~min}$. Subjects had to respond to brief (1 or $2 \mathrm{~s}$ ) light pulses randomized across these locations in order to gain liquid reward. The initial training schedule continued for 40 sessions or until mice reached asymptotic performance at $1 \mathrm{~s}$ stimulus duration and performance was measured by accuracy, calculated as total correct responses/total responses. At the end of the initial training phase, animals were returned to free access to food and water. The two retraining phases were started 4 months after the previous phase ended and took approximately 2 months to complete. Retraining began with the $10 \mathrm{~s}$ stimulus duration and decreased to $2 \mathrm{~s}$ as previously described. ${ }^{55}$ Therefore, asymptotic performance was assessed when mice were 14-, 20- and 27-month old. Group sizes reduced slightly over time: $n=6$ and 5 for transgenic and WT mice, respectively, at 20 months and $n=3$ per group at 27 months. As group sizes reduced over time, a repeated measures analysis was inappropriate and data were therefore analysed by two-way ANOVA using transgene and age as the main factors.

\section{Cerebral ischaemia}

Monofilament occlusion of the middle cerebral artery (MCA) was performed in adult male transgenic mice and WT littermates $(25-30 \mathrm{~g}$, approximately 10-12 weeks) using a modification of the method described 
by Hata et al. ${ }^{76}$ Briefly, the right common carotid (CCA), external carotid (ECA) and internal carotid (ICA) arteries and their branches were exposed through a midline cervical incision. A 6-0 silk suture was tied around the CCA proximal to the bifurcation of the ECA and ICA and a second suture tied around the ECA distal to the superior thyroid artery (STA). The STA and occipital artery $(\mathrm{OA})$ were occluded by electrocoagulation. An 8-0 silicone-coated monofilament (diameter $220 \mu \mathrm{m}$ ) was introduced into the CCA and advanced $10 \mathrm{~mm}$ distal to the carotid bifurcation, occluding the origin of the MCA. Transgenic animals and their WT littermates were subjected to 30 ( $n=8-9$ per group), 45 ( $n=6-7$ per group) or 60 ( $n=5-$ 6 per group) minutes of ischaemia and killed at $24 \mathrm{~h}$ by trans-cardiac perfusion with $4 \%$ paraformaldehyde under deep anaesthesia (pentobarbitone, $60 \mathrm{mg} / \mathrm{kg}$ i.p.). Brains were removed and processed for quantitative histological analysis. Cryostat sections $(20 \mu \mathrm{m})$ were stained with thionin and examined for damage at nine stereotaxic levels by light microscopy. Image analysis (MCID, Interfocus Ltd, Haverhill, Suffolk, UK) was used to determine the volume of damage. Transgenic and WT littermate mice were compared using two-way analysis of variance. Genotyping was carried out at 4 weeks of age and confirmed prior to final analysis of the data.

\section{Immunohistochemistry of cleaved caspase-3 and TUNEL staining}

Caspase 3 transgenic $(n=3)$ and WT animals $(n=3)$ were subjected to $30 \mathrm{~min}$ of ischaemia. Animals were killed at $24 \mathrm{~h}$ and the brains removed and immediately frozen $\left(-42^{\circ} \mathrm{C}\right.$ ) in M-1 Embedding Matrix (Lipshaw Co. Ltd, Pittsburgh, PA, USA). Cryostat sections $(10 \mu \mathrm{m})$ were mounted onto TESPA slides and dried at $37^{\circ} \mathrm{C}$ for $1 \mathrm{~h}$. The sections were acetone-fixed for $10 \mathrm{~min}$ at room temperature, air dried and then kept $-70^{\circ} \mathrm{C}$ until processed. Slides were blocked for $1 \mathrm{~h}$ in $3 \%$ BSA, Tris-buffered saline, $1 \%$ Tween 20 then incubated at $4^{\circ} \mathrm{C}$ overnight in primary antibody against cleaved caspase 3 (Cell Signaling Technology; 1/20 dilution in block). After washing, bound antibody was detected using Cy-3 conjugated goat antirabbit (Amersham Biosciences; $1 / 200$ in 1\% BSA). TUNEL staining was performed with ApoTag In Situ Apoptosis Detection Kit (Appligene/Oncor, Chester-Le-Street, Co. Durham, UK). Caspase 3 and TUNEL-positive cells in the ischaemic striatum of transgenic and WT animals were counted in five brain sections per animal and analysed using Student's $t$-test.

\section{Acknowledgements}

The assistance of Elma Clark (MRC Brain Metabolism Unit, Edinburgh), Harris Morrison and Dr. Paul Perry (both MRC Human Genetics Unit, Western General Hospital, Edinburgh) in performing the FISH analysis is gratefully acknowledged. The authors also wish to thank Dr. Colin Smith (Department of Pathology, University of Edinburgh) for his assessment of histological sections.

\section{References}

1. Alnemri ES (1997) Mammalian cell death proteases: a family of highly conserved aspartate specific cysteine proteases. J. Cell Biochem. 64: 33-42

2. Thornberry NA and Lazebnik Y (1998) Caspases: enemies within. Science 281 1312-1316

3. Yuan J, Shaham S, Ledoux S, Ellis HM and Horvitz HR (1993) The C. elegans cell death gene ced-3 encodes a protein similar to mammalian interleukin- $1 \beta$ converting enzyme. Cell 75: 641-652

4. Cryns V and Yuan J (1998) Proteases to die for. Genes Dev. 12: 1551-1570
5. Fischer U, Janicke RU and Schulze-Osthoff K (2003) Many cuts to ruin: a comprehensive update of caspase substrates. Cell Death Differ. 10: 76-100

6. Slee EA, Harte MT, Kluck RM, Wolf BB, Casiano CA, Newmeyer DD, Wang HG, Reed JC, Nicholson DW, Alnemri ES, Green DR and Martin SJ (1999) Ordering the cytochrome-c initiated caspase cascade: hierarchical activation of caspases-2, $-3,-6,-7,-8$ and -10 in a caspase- 9 dependent manner. J. Biol. Chem. 144: 281-292

7. Kang JJ, Schaber MD, Srinivasula SM, Alnemri ES, Litwack G, Hall DJ and Bjornsti MA (1999) Cascades of mammalian caspase activation in the yeast Saccharomyces cerevisiae. J. Biol. Chem. 274: 3189-3198

8. Sun XM, MacFarlane M, Zhuang J, Wolf BB, Green DR and Cohen GM (1999) Distinct caspase cascades are initiated in receptor-mediated and chemicalinduced apoptosis. J. Biol. Chem. 274: 5053-5060

9. Slee EA, Adrain C and Martin SJ (2001) Executioner caspases-3, -6 and -7 perform distinct, non-redundant, roles during the demolition phase of apoptosis. J. Biol. Chem. 276: 7320-7326

10. Kuida K, Zheng TS, Na S, Kuan C, Yang D, Karasuyama H, Rakic P and Flavell RA (1996) Decreased apoptosis in the brain and premature lethality in CPP32deficient mice. Nature 384: 368-372

11. Zheng TS, Hunot S, Kuida K, Momoi T, Srinivasan A, Nicholson DW, Lazebnik $Y$ and Flavell RA (2000) Deficiency in caspase-9 or caspase-3 induces compensatory caspase activation. Nat. Med. 6: 1241-1247

12. Ni B, Wu X, Su Y, Stephenson D, Smalstig EB, Clemens J and Paul SM (1998) Transient global forebrain ischemia induces a prolonged expression of the caspase-3 mRNA in rat hippocampal CA1 neurons. J. Cereb. Blood Flow Metab. 18: 248-256

13. Chen J, Nagayama T, Jin K, RA, Zhu RL, Graham SH and Simon RP (1998) Induction of caspase-3-like protease may mediate delayed neuronal death in the hippocampus after transient cerebral ischemia. J. Neurosci. 18: 4914-4928

14. Endres M, Namura S, Shimizu-Sasamata M, Waeber C, Zhang L, Gomez-Isla T, Hyman BT and Moskowitz MA (1998) Attenuation of delayed neuronal death after mild focal ischemia in mice by inhibition of the caspase family. J. Cereb. Blood Flow Metab. 18: 238-247

15. Fink K, Zhu J, Namura S, Shimizu-Sasamata M, Endres M, Ma J, Dalkara T, Yuan J and Moskowitz MA (1998) Prolonged therapeutic window for ischemic brain damage caused by delayed caspase activation. J. Cereb. Blood Flow Metab. 18: 1071-1076

16. Namura S, Zhu J, Fink K, Endres M, Srinivasan A, Tomaselli KJ, Yaun J and Moskowitz MA (1998) Activation and cleavage of caspase-3 in apoptosis induced by experimental cerebral ischemia. J. Neurosci. 18: 3659-3668

17. Benchoua A, Guegan C, Couriaud C, Hosseini H, Sampaio N, Morin D and Onteniente $B$ (2001) Specific caspase pathways are activated in the two stages of cerebral infarction. J. Neurosci. 21: 7127-7134

18. Davoli MA, Fourtounis J, Tam J, Xanthoudakis S, Nicholson D, Robertson GS, $\mathrm{Ng} \mathrm{GY}$ and Xu D (2002) Immunohistochemical and biochemical assessment of caspase-3 activation and DNA fragmentation following transient focal ischemia in the rat. Neuroscience 115: 125-136

19. Zhao H, Yenari MA, Cheng D, Sapolsky RM and Steinberg GK (2003) Bcl-2 overexpression protects against neuron loss within the ischemic margin following experimental stroke and inhibits cytochrome $c$ translocation and caspase-3 activity. J. Neurochem. 85: 1026-1036

20. Hayashi T, Sakurai M, Abe K, Sadahiro M, Tabayashi K, Itoyama $Y$ and Chan $\mathrm{PH}$ (1998) Apoptosis of motor neurons with induction of caspases in the spinal cord after ischemia. Stroke 29: 1007-1013

21. Cheng Y, Deshmukh M, D'Costa A, Demaro JA, Gidday JM, Shah A, Sun Y, Jacquin MF, Johnson EM and Holtzman DM (1998) Caspase inhibitor affords neuroprotection with delayed administration in a rat model of neonatal hypoxicischemic brain injury. J. Clin. Invest. 101: 1992-1999

22. Bossenmeyer-Pourie C, Koziel V and Daval JL (1999) CPP32/CASPASE-3-like proteases in hypoxia-induced apoptosis in developing brain neurons. Mol. Brain Res. 71: 225-237

23. Zhu C, Wang X, Hagberg $H$ and Blomgren $K$ (2000) Correlation between caspase-3 activation and three different markers of DNA damage in neonatal cerebral hypoxia-ischemia. J. Neurochem. 75: 819-829

24. Yakovlev AG, Knoblach SM, Fan L, Fox GB, Goodnight R and Faden Al (1997) Activation of CPP32-like caspases contributes to neuronal apoptosis and neurological dysfunction after traumatic brain injury. J. Neurosci. 17: 7415-7424 
25. Pike BR, Zhao X, Newcombe JK, Posmantur RM, Wang KKW and Hayes RL (1998) Regional calpain and caspase-3 proteolysis of $\alpha$-spectrin after traumatic brain injury. NeuroReport 9: 2437-2442

26. Beer R, Franz G, Srinivasan A, Hayes RL, Pike BR, Newcomb JK, Zhao X, Schmutzhard E, Poewe W and Kampfl A (2000) Temporal profile and cell subtype distribution of activated caspase-3 following experimental traumatic brain injury. J. Neurochem. 75: 1264-1273

27. Gervais FG, Xu D, Robertson GS, Vaillancourt JP, Zhu Y, Huang J, LeBlanc A, Smith D, Rigby M, Shearman MS, Clarke EE, Zheng H, Van der Ploeg LHT, Ruffolo SC, Thornberry NA, Xanthoudakis S, Zamboni RJ, Roy S and Nicolson DW (1999) Involvement of caspases in proteolytic cleavage of Alzheimer's amyloid-beta precursor protein and amyloidogenic A-beta formation. Cell 97: 395-406

28. Weidemann A, Paliga K, Durrwang U, Reinhard FB, Schuckert O, Evin G and Masters CL (1999) Proteolytic processing of the Alzheimer's disease amyloid precursor protein within its cytoplasmic domain by caspase-like proteases. J. Biol. Chem. 274: 5823-5829

29. Su JH, Zhao M, Anderson AJ, Srinivasan A and Cotman CW (2001) Activated caspase-3 expression in Alzheimer's and aged control brain: correlation with Alzheimer pathology. Brain Res. 898: 350-357

30. Goldberg YP, Nicholson DW, Rasper DM, Kalchman MA, Koide HB, Graham RK, Bromm M, Kazemi-Esfarjani P, Thornberry NA, Vaillancourt JP and Hayden MR (1996) Cleavage of huntingtin by apopain, a pro-apoptotic cysteine protease, is modulated by the polyglutamine tract. Nat. Genet. 13: 442-449

31. Chen M, Ona VO, Li M, Ferrante RJ, Fink KB, Zhu S, Bian J, Guo L, Farrell LA Hersch SM, Hobbs W, Vonsattel J, Cha JJ and Friedlander RM (2000) Minocycline inhibits caspase- 1 and caspase- 3 expression and delays mortality in a transgenic mouse model of Huntington disease. Nat. Med. 6: 797-801

32. Wellington CL, Ellerby LM, Gutekunst CA, Rogers D, Warby S, Graham RK, Loubser O, van Raamsdonk J, Singaraja R, Yang YZ, Gafni J, Bredesen D, Hersch SM, Leavitt BR, Roy S, Nicholson DW and Hayden MR (2002) Caspase cleavage of mutant huntingtin precedes neurodegeneration in Huntington's disease. J. Neurosci. 22: 7862-7872

33. Hartmann A, Hunot S, Michel PP, Muriel MP, Vyas S, Faucheux BA, MouattPrigent A, Turmel H, Srinivasan A, Ruberg M, Evan GI, Agid Y and Hirsch EC (2000) Caspase-3: a vulnerability factor and final effector in apoptotic death of dopaminergic neurons in Parkinson's disease. Proc. Natl. Acad. Sci. USA 97: 2875-2880

34. Mogi $\mathrm{M}$, Togari $\mathrm{A}$, Kondo $\mathrm{T}$, Mizuno $\mathrm{Y}$, Komure $\mathrm{O}$, Kuno $\mathrm{S}$, Ichinose $\mathrm{H}$ and Nagatsu T (2000) Caspase activities and tumor necrosis factor receptor R1 (p55) level are elevated in the substantia nigra from Parkinsonian brain. J. Neural Transm. 107: 335-341

35. Tatton NA (2000) Increased caspase 3 and Bax immunoreactivity accompany nuclear GAPDH translocation and neuronal apoptosis in Parkinson's disease. Exp. Neurol. 166: 29-43

36. Turmel H, Hartmann A, Parain K, Douhou A, Srinivasan A, Agid $Y$ and Hirsch EC (2001) Caspase-3 activation in 1-methyl-4-phenyl-1,2,3,6tetrahydropyridine (MPTP)-treated mice. Mov. Disord. 16: 185-189

37. Tatton WG, Chalmers-Redman R, Brown D and Tatton N (2003) Apoptosis in Parkinson's disease: signals for neuronal degradation. Ann. Neurol. 53: S61-S72

38. Nasir J, Theilmann JL, Chopra V, Jones AM, Walker D, Rasper DM, Vaillancourt JP, Hewitt JE, Nicholson DW and Hayden MR (1997) Localization of the cell death genes CPP32 and Mch-2 to human chromosome 4q. Mamm. Genome 8: 56-59

39. Jones DNA, Barnes JC, Kirkby DL and Higgins GA (1995) Age-associated impairments in a test of attention: evidence for involvement of cholinergic systems. J. Neurosci. 15: 7282-7292

40. Chen WJ, Hsaio CK, Hsaio LL and Hwu HG (1998) Performance of the continuous performance test among community samples. Schizophr. Bull. 24: 163-174

41. Tiso N, Pallavicini A, Muraro T, Zimbello R, Apolloni E, Valle G, Lanfranchi G and Danieli GA (1996) Chromosomal localization of the human genes, CPP32, Mch2, Mch3, and Ich-1, involved in cellular apoptosis. Biochem. Biophys. Res. Commun. 225: 983-989

42. Hammes A and Schedl A (2000) Generation of transgenic mice from plasmids, BACs and YACs. In Mouse Genetics and Transgenics: A Practical Approach, Jackson IJ and Abbott CM eds (New York: Oxford University Press) pp. 217-245
43. Juan TSC, McNiece IK, Jenkins NA, Gilbert D, Copeland NG and Fletcher FA (1996) Molecular characterization of mouse and rat CPP32 $\beta$ gene encoding a cysteine protease resembling interleukin-1 $\beta$ converting enzyme and CED-3. Oncogene 13: 749-755

44. Pompeiano M, Blaschke AJ, Flavell RA, Srinivasan A and Chun J (2000) Decreased apoptosis in proliferative and postmitotic regions of the caspase 3-deficient embryonic central nervous system. J. Comp. Neurol. 423: 1-12

45. Wheeler DL, Church DM, Federhen S, Lash AE, Madden TL, Pontius JU, Schuler GD, Schriml LM, Sequeira E, Tatusova TA and Wagner L (2003) Database resources of the National Center for Biotechnology. Nucleic Acids Res. 31: 28-33

46. Liu W, Wang G and Yakovlev AG (2002) Identification and functional analysis of the rat caspase-3 gene promoter. J. Biol. Chem. 277: 8273-8278

47. Ashe PC and Berry MD (2003) Apoptotic signalling cascades. Prog. NeuroPsychopharmacol. Biol. Psychiatry 27: 199-214

48. Armstrong RC, Aja TJ, Hoang KD, Gaur S, Bai X, Alnemri ES, Litwack G, Karanewsky DS, Fritz LC and Tomaselli KJ (1997) Activation of the CED3/ICErelated protease CPP32 in cerebellar granule neurons undergoing apoptosis but not necrosis. J. Neurosci. 17: 553-562

49. Allsopp TE, McLuckie J, Kerr LE, Macleod M, Sharkey JS and Kelly JS (2000) Caspase 6 activity initiates caspase 3 activation in cerebellar granule cell apoptosis. Cell Death Differ. 7: 984-993

50. Parasuraman R, Nestor P and Greenwood P (1989) Sustained-attention capacity in young and older adults. Psychol. Aging 4: 339-345

51. Berardi A, Parasuraman R and Haxby JV (2001) Overall vigilance and sustained attention decrements in healthy aging. Exp. Aging Res. 27: 19-39

52. Muir JL, Fischer W and Bjorklund A (1999) Decline in visual attention and spatial memory in aged rats. Neurobiol. Aging 20: 605-615

53. Grottick AJ and Higgins GA (2002) Assessing a vigilance decrement in aged rats: effects of pre-feeding, task manipulation, and psychostimulants. Psychopharmacology 164: 33-41

54. Humby T, Laird FM, Davies W and Wilkinson LS (1999) Visuospatial attentional functioning in mice: interactions between cholinergic manipulations and genotype. Eur. J. Neurosci. 11: 2813-2823

55. Young JW, Finlayson K, Spratt C, Marston HM, Crawford N, Kelly JS and Sharkey J (2003) Nicotine improves sustained attention in mice: evidence for involvement of the alpha 7 nicotinic acetylcholine receptor. Neuropsychopharm. 29: $891-900$

56. Hara H, Friedlander RM, Gagliardini V, Ayata C, Fink K, Huang Z, ShimizuSasamata M, Yuan J and Moskowitz MA (1997) Inhibition of interleukin 1 beta converting enzyme family proteases reduces ischemic and excitotoxic damage. Proc. Natl. Acad. Sci. USA 94: 2007-2012

57. Robertson GS, Crocker SJ, Nicholson DW and Schulz JB (2000) Neuroprotection by the inhibition of apoptosis. Brain Pathol. 10: 283-292

58. Yang W, Guastella J, Huang JC, Wang Y, Zhang L, Xue D, Tran M, Woodward R, Kasibhatla S, Tseng B, Drewe J and Cai SX (2003) MX1013, a dipeptide caspase inhibitor with potent in vivo antiapoptotic activity. Br. J. Pharmacol. 140: 402-412

59. Le DA, Wu Y, Huang Z, Matsushita K, Plesnila N, Augustinack JC, Hyman BT, Yuan J, Kuida K, Flavell RA and Moskowitz MA (2002) Caspase activation and neuroprotection in caspase-3-deficient mice after in vivo cerebral ischemia and in vitro oxygen glucose deprivation. Proc. Natl. Acad. Sci. USA 99: $15188-15193$

60. Condorelli G, Roncarati R, Ross J, Pisani A, Strassi G, Todaro M, Trocha S, Drusco A, Gu Y, Russo MA, Frati G, Jones SP, Lefer DJ, Napoli C and Croce CM (2001) Heart-targeted overexpression of caspase 3 in mice increases infarct size and depresses cardiac function. Proc. Natl. Acad. Sci. USA 98: 9977-9982

61. Hata R, Maeda K, Hermann D, Mies G and Hossmann KA (2000) Evolution of brain infarction after transient focal ischaemia in mice. J. Cereb. Blood Flow Metab. 20: 937-946

62. Hermann DM, Kilic E, Hata R, Hossmann KA and Miles G (2001) Relationship between metabolic dysfunctions, gene responses and delayed cell death after mild focal cerebral ischemia in mice. Neuroscience 104: 947-955

63. Wheeler RD, Bouting H, Touzani O, Luheshi GN, Takeda K and Rothwell NJ (2003) No role for interleukin-18 in acute murine stroke-induced brain injury. J. Cereb. Blood Flow Metab. 23: 531-535 
64. Leonard JR, Klocke BJ, D'Sa C, Flavell RA and Roth KA (2002) Straindependent neurodevelopmental abnormalities in caspase-3-deficient mice. J. Neuropathol. Exp. Neurol. 61: 673-677

65. Momoi T, Fujita E and Urase K (2003) Strain-specific caspase-3-dependent programmed cell death in the early developing mouse forebrain. NeuroReport 14: $111-115$

66. Mattson MP (2000) Apoptotic and antiapoptotic synaptic signalling mechanisms Brain Pathol. 10: 300-312

67. McLaughlin BA, Hartnett KA, Erhart JA, Legos JL, White RF, Barone FC and Aizenman E (2003) Caspase 3 activation is essential for neuroprotection in preconditioning. Proc. Natl. Acad. Sci. USA 100: 715-720

68. Anand R, Riley JH, Butler R, Smith JC and Markham AF (1990) A 3.5 genome equivalent multi access YAC library: construction, characterisation, screening and storage. Nucleic Acids Res. 18: 1951-1956

69. Bellis M, Pages M and Roizes G (1987) A simple and rapid method for preparing yeast chromosomes for pulse field gel electrophoresis. Nucleic Acids Res. 15: 6749

70. Leversha MA (1997) Fluorescence in situ hybridization. In Genome Mapping: A Practical Approach, Dear P ed (New York: Oxford University Press) pp. 199-225
71. Hogan B, Beddington R, Costantini F and Lacey E (1994) Manipulating the Mouse Embryo: A Laboratory Manual, second edition. (New York: Cold Spring Harbor Laboratory Press)

72. Schedl A, Grimes B and Montoliu L (1996) YAC transfer by microinjection. Methods Mol. Biol. 54: 293-306

73. Sambrook J and Russell DW (2001) Molecular Cloning: A Laboratory Manual, third edition (New York: Cold Spring Harbor Laboratory Press)

74. Hakem R, Hakem A, Duncan GS, Henderson JT, Woo M, Soengas MS, Elia A, de la Pompa JL, Kagi D, Khoo W, Potter J, Yoshida R, Kaufman SA, Lowe SW, Penninger JM and Mak TW (1998) Differential requirement for caspase 9 in apoptotic pathways in vivo. Cell 94: 339-352

75. Fox M and Povey S (2000) Fluorescent in situ hybridization (FISH) to mouse chromosomes. In Mouse Genetics and Transgenics: A Practical Approach, Jackson IJ and Abbott CM eds (New York: Oxford University Press) pp. 154-169

76. Hata R, Mies $G$, Wiessner $C$, Fritze $K$, Hesselbarth D, Brinker $G$ and Hossmann KA (1998) A reproducible model of middle cerebral artery occlusion in mice: hemodynamic, biochemical, and magnetic resonance imaging. J. Cereb. Blood Flow Metab. 18: 367-375 